\title{
QUANDO DIZER É AGIR: RACISMO NO PODER DAS PALAVRAS
}

Jarbas Vargas Nascimento

O agir (...) corresponde à passagem da potencialidade à existência (Greimas)

O presente capítulo insere-se na Análise do Discurso de linha francesa (AD), em interdisciplinaridade com os Estudos Culturais (EC), na medida em que nos permitem questionar a palavra, nas interações sociais, quando relacionadas a domínio sobre o outro. A aliança dessas disciplinas nos faz pensar a língua nas práticas sociais, onde articulam dimensões discursivas e histórico-culturais. Privilegiamos a abordagem discursiva para propor o estudo de palavras e de sequências lexicais como integrantes de um processo sócio-histórico-cultural, incluindo nele o sujeito negro e os efeitos de sentido racistas que recaem sobre ele. Para tal, consideramos as palavras selecionadas como referências identitárias e uma herança histórico-cultural, que sobrepõe ao sujeito negro 
uma condição de inferioridade imposta pelo sujeito branco na sociedade brasileira.

Justificam-se nosso tema e a nossa proposta de produção desse capítulo o fato de que as escolhas lexicais pelo sujeito falante funcionam como uma estratégia discursiva, essencial na reflexão sobre o racismo, pois elas são carregadas de posicionamentos e permitem-nos desvendar comportamentos de dominação, de hierarquização e de discriminação, que facilitam sua naturalização. Recortamos o seguinte trecho de Vilela (1994, p.6), que reforça o que estamos refletindo.

O léxico é a parte da língua que primeiramente configura a atividade extralinguística e que arquiva o saber linguístico duma comunidade. Avanços e recuos civilizacionais, descobertas e eventos, encontro entre povos e culturas, crenças, afinal quase tudo, antes de passar para a língua e para a cultura dos povos, tem um nome e esse nome faz parte do léxico. O léxico é o repositório do saber linguístico e é ainda a janela através da qual um povo vê o mundo. Um saber partilhadoi que existe na cosnciência dos falantes duma comunidade.

Dessa maneira, acreditamos que por esse estudo interdisciplinar, possamos explicitar marcas enunciativas do racismo estrutural e o apagamento proposital da identidade cultural do sujeito negro brasileiro. Esse ponto de vista leva-nos a considerar, ainda, com base na AD, nas perspectivas de Maingueneau (2005), a enunciação léxico-discursiva como uma atividade linguageira exercida pelo usuário da língua no momento em que fala, ou seja, no instante em que a discursividade se concretiza. $\mathrm{O}$ fato de a palavra 
ser uma produção humana, destituída de autoralidade, conforme postula Turazza (2005), ela pode circular na/pela sociedade, materializando carga semântica de caráter ideológico e, consequentemente, explicitando os posicionamentos daqueles que a enunciam em diferentes atos de fala.

Nesse cenário, queremos verificar tanto a carga semântica constitutiva da palavra, configurada por matrizes culturais quanto a maneira como o sujeito se coloca na cena enunciativa, para evidenciar a si e negociar efeitos de sentido. Nessa perspectiva, o uso de certas palavras implica a manifestação do posicionamento do sujeito falante, precisa ser reavaliado e reconstruído, a partir de uma mudança na cosmovisão do outro, quando geram efeitos maléficos à vida. Podemos dizer que os Estudos Culturais desenvolveram abordagens que, em diferentes aspectos, dialogam com a $\mathrm{AD}$, principalmente, quando nos referimos à cultura negra, africana, em relação à cultura branca, eurocêntrica.

Para o desenvolvimento desse tema, priorizamos uma abordagem discursiva, pois entendemos a palavra como um plano de uma semântica global e, por isso, uma marca de cristalização semântica de múltiplos posicionamentos, nas atividades sociodiscursivas. Além disso, de acordo com Maingueneau (1996), a semântica global de um discurso permite-nos apreender o sujeito, quando do ato de enunciação. Por essa razão, investigamos, também, o uso de determinadas palavras, que circulam em nossa comunidade discursiva, isto é, fazem-se presentes na ordem dos acontecimentos de nossa sociedade e que, por isso, devem ser revisitadas e, constantemente, ressignificadas, pois adquirem estatuto de signo de pertencimento.

Há diferentes perspectivas teórico-metodológicas, na Linguística, que buscam conceituar o que chamamos de sequências 
lexicais. No entanto, destacamos aqui a expressão sequência lexical no sentido de elocução, conceito estudado por Casares (1950), quando nomeia a junção de duas ou mais palavras, que se comportam como uma unidade semântica, conforme observamos em alma negra, asa negra, besta negra, lista negra, magia negra, ovelha negra, peste negra, câmbio negro, humor negro, mercado negro, que integram a lista selecionada como amostragem e que nos dão uma visão de como elas podem produzir, além de seus valores semânticos dicionarizados, efeitos de sentido discriminatórios em práticas interativas. Sequências lexicais como essas estão em circulação na sociedade brasileira e sua produtividade semântica garante ao falante crenças, que mobilizam e expressam atitude linguística de preconceito racial e de racismo relativos ao universo do sujeito negro.

Em época de avanços na concepção e valorização do sujeito, de discussão sobre a contribuição étnica para a cultura brasileira e de debate sobre a condição do negro fora e dentro do Brasil, não há como não repelir o racismo estrutural e institucional, que afeta a nossa sociedade, sem fundamento e sem justificativa racionais. Não resta dúvida de que a escravização negra, articulada com base na bandeira da violência física, marcou seriamente a condição humana desse sujeito. Por conta disso e pela elaboração de valores culturais e de sua cristalização na sociedade brasileira, faz-se necessário reparar esse dado histórico e, ainda, ressaltar a contribuição do negro na construção de nossa história como nos lembra Araújo (2007, p.5), quando assim expressa:

Penso, por fim, na ambiguidade desta nossa história de que são vítimas os negros, numa sociedade que os exclui dos benefícios da vida social, mas que, no entanto, consome os deuses do candomblé, a música, a dança, a co- 
mida, a festa, todas as festas de negros, esquecida de suas origens. E penso também em como, em vez de registrar simplesmente ofracasso dos negros frente às tantas e inumeráveis injustiças sofridas, esta história termina por registrar a sua vitória e a sua vingança, em tudo o que eles foram capazes de fazer para incorporar-se à cultura brasileira. Uma cultura que guarda, através de sua história, um rastro profundo de negros africanos e brasileiros, mulatos e cafuzos, construtores silenciosos de nossa identidade. Enão se pode dizer que não houve afetividade ou cumplicidade nessa relação. A mestiçagem é a maior prova dessa história de pura sedução, da sedução suscitada pela diferença, que ameaça e atrai, mas acaba sendo incorporada como convívio tenso e sedutor, em todos os momentos da nossa vida. Tudo isso é memória. Tudo isso faz parte da nossa história. Uma história escamoteada que já não poderá mais ficar esquecida pela história oficial.

Interessa-nos, por isso, nesse capítulo, a abordagem cultural e semântico-discursiva das palavras selecionadas, pois sua enunciação não se restringe apenas à descrição de um estado de coisas, mas a uma forma de realização de determinada intencionalidade, incorporada a um processo de dominação, hierarquização e violência exercida sobre os negros, desde o Brasil-colônia. Essa atitude de dominação funciona como uma espécie de ameaça à igualdade social, corroborando, por conseguinte, para a exclusão e apagamento identitário do negro. Em vista disso, é-nos urgente inferir os pressupostos discursivos e sócio-histórico-culturais que, pela linguagem, geram a invisibilidade e inferioridade do negro e 
refletem condutas intolerantes acumuladas ao longo da história do Brasil, como comprova Araújo (2007) na reflexão acima.

De fato, queremos nos apoiar na noção de sujeito e de sua relação com determinadas palavras e sequências lexicais, veiculadas em nossa sociedade, filtradas por uma cultura racial, pois o indivíduo se constitui em sujeito, fonte de sentido, ao enunciar, pois imbrica intencionalidade e efeitos de sentido. Essa constatação nos leva à compreensão de que a geração de efeitos de sentido está relacionada à constituição de sujeito. Por esse motivo, a partir da amostra selecionada, objetivamos examinar o investimento intersubjetivo do posicionamento do sujeito falante e sua relação com a questão racial, que nos propicia o entendimento hierarquizado entre negros e brancos e comprova atitudes e comportamentos sócio-historicamente de exclusão contra a população negra.

Nosso estudo emerge, por conseguinte, da ocorrência de conduta agressiva e violenta do sujeito branco, usuário da língua quando, na interação, escolhe unidades e sequências lexicais, reguladas por um sistema de restrição semântica que, à vista disso, nos abre a possibilidade de relacionar determinado uso linguístico ao racismo, inscrito no processo de discursivização sócio-histórico-cultural brasileiro. Apreender essa amostra, de um ponto de vista discursivo e histórico-cultural, parece-nos pertinente, já que temos consciência de que as palavras efetivam seu conteúdo na enunciação linguística e, nesse sentido, reivindicam contínua atualização semântica, em virtude de múltiplas e diferentes formações discursivas, que incidem sobre elas.

Face a nosso propósito, buscamos respaldo, também, no pressuposto primordial de que a palavra e as sequências lexicais são polissêmicas, abrigam inúmeros efeitos de sentido e trazem à memória posicionamentos, pensamentos, atitudes, pontos de vista e 
valores naturalizados na mente do sujeito falante. Empregadas por diferentes sujeitos, a palavra negocia efeitos de sentido, que carregam particularidades da história, da cultura e, inclusive, da política que, na concepção de Bobbio (2000), se refere ao poder que um sujeito exerce sobre o outro. Dizendo de outro modo, argumentamos que a lista de palavras que selecionamos nos possibilita a criação de um simulacro de discurso de poder do branco sobre o negro que nos autoriza a não ignorá-la em virtude das restrições, que lhe são impostas devido ao conceito de raça, criado para justificar a escravização.

Além disso, concordamos com Orlandi (2003, p.42), quando a autora reitera que o sentido é determinado pelas posições ideológicas colocadas em jogo no processo sócio-histórico em que as palavras são produzidas. Por esse modo de pensar e, tendo em vista essa perspectiva discursiva, supomos que nossa reflexão possa contribuir com os estudos que, no processo de comunicação, buscam evidenciar poder de um sobre o outro, identificando aspectos negativos impostos à constituição da identidade do sujeito negro, no universo sociocultural do Brasil.

É nesse cenário que a discussão proposta, para esse capítulo, se alicerça. De fato, nossa investigação se respalda na tese de que a palavra, pronunciada em determinada condição enunciativa, materializa um posicionamento do sujeito e negocia efeitos de sentido benéficos ou maléficos, no processo discursivo de interação. Reforça-nos essa perspectiva o entendimento de Charaudeau (2001), que nos faz lembrar do processo de interação entre sujeitos e a atividade linguageira de poder que o falante tem sobre o outro. Charaudeau postula que o sujeito comunicante negocia efeitos de sentido à palavra enunciada e, acima de tudo, considera seu lugar, a situação e o momento em que esse sujeito enuncia. 
Do que antecede, podemos esclarecer, a título de evidenciação, o que ocorre com a palavra denegrir que, no Dicionário Houaiss online de Língua Portuguesa, refere-se a preto, escuro, mancha, sujeira. Em um enfoque enunciativo, podemos dizer que os sentidos fixados pelo/no dicionário funcionam como um mobilizador de conhecimentos e permitem, inclusive, contratos, que se ampliam nas cenas de enunciação, onde o dito e o dizer se sustentam reciprocamente (Maingueneau, 2006).

No Dicionário Online de Português, há para denegrir as seguinte acepções, conforme apresentamos a seguir:

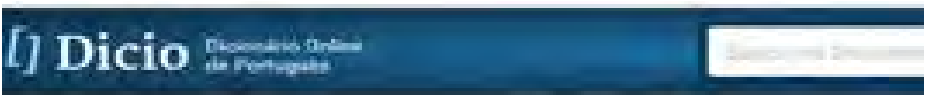

\section{denegrix}

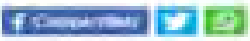

\section{Significado de Denegrir}

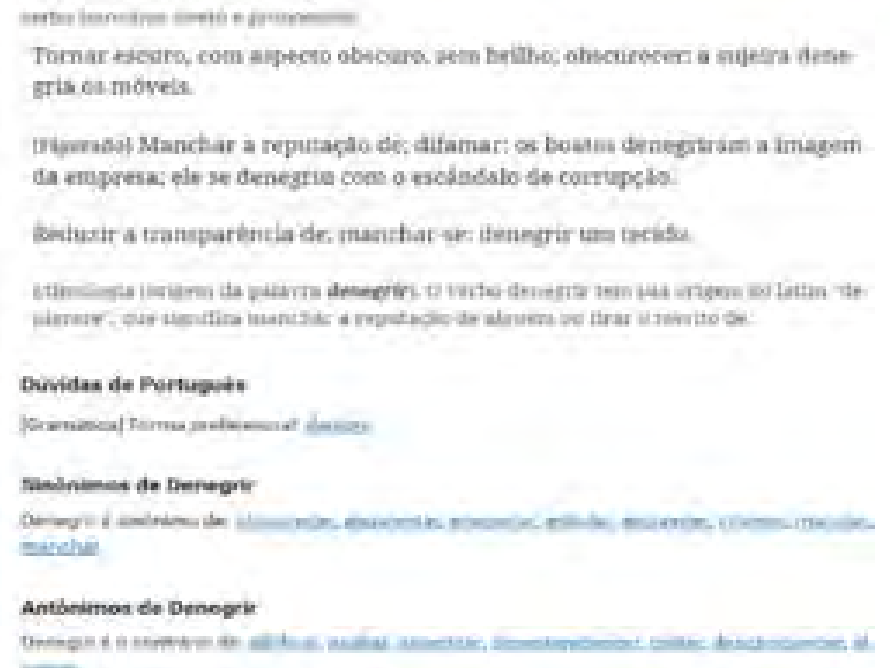

나요

Como podemos observar, no Dicionário online, denegrir significa tornar escuro, com aspecto obscuro, sem brilho; obscure- 
cer: a sujeira denegria os móveis. Em sentido figurado manchar a reputação de; difamar. Reduzir a transparência de; manchar-se: denegrir um tecido. Do ponto de vista etimológico, a palavra denegrir tem sua origem do latim "denigrare", que significa manchar a reputação de alguém ou tirar o mérito de. Forma preferencial: denigrir.

Sinônimos de denegrir: obscurecer, aguarentar, enegrecer, enlodar, escurecer, infamar, macular, manchar.

Antônimos de denegrir: albificar, exaltar, argentear, desentenebrecer, calear, desobscurecer, alvescer.

$\mathrm{Na}$ etimologia da palavra denegrir, verificamos que sua composição nos remete à preposição latina de, que exprime proveniência, causa, instrumento, posse, modo, dimensão, agente, carácter, estado, profissão, mais o adjetivo niger, que significa negro, preto, escuro, qualificação atribuída a sujeitos de pele negra ou atributo do negro (escuro). Nesse verbete, como explícito no Dicionário Houaiss online, denegrir carrega a carga semântica de manchar a reputação de, enegrecer, manchar. Embora como um recurso de comunicação, o uso de denegrir, na enunciação, confere à cena enunciativa certa característica, na medida em que ali o falante é impulsionado a ter o que dizer e a definir-se a si mesmo por sua capacidade de expressar-se linguisticamente e de interagir com o outro pela forma como toma a palavra naquele ato de fala. Como a palavra está em cada um de nós e traz consigo seu conteúdo naturalizado sócio-histórico e culturalmente, ela suscita a adesão do ouvinte pela maneira de dizer de cada falante, que se confunde com sua maneira de ser.

Consta, de fato, que os adjetivos negro/negra, preto/preta foram usados com carga pejorativa, desde o início do século XX, nos 
Estados Unidos, familiarizados com um posicionamento racista. Talvez tenha sido os antônimos de denegrir: albificar, exaltar, argentear, desentenebrecer, calear, desobscurecer, alvescer de onde se poderia ter apreendido e fixado uma atitude racializada no espaço discursivo, ao se integrar à carga semântica de denegrir a seu sentido figurado e a seu antônimo, como exposto no dicionário.

De fato, o dicionário tem uma função decodificadora e seu objetivo é ajudar-nos a compreender o sentido das palavras; entretanto é, na enunciação, que o usuário da língua dinamiza o sentido, constrói outros e negocia efeitos de sentido, que coloca o dicionário em segundo plano. Por isso, embora partamos do dicionário é, na cena enunciativa, em um processo sociointerativo, que o falante mostra sua subjetividade por meio de estratégias ativas e criativas só possível pela linguagem. Seguramente, é pela linguagem, fenômeno biológico e cultural, que o falante se inscreve em um sistema semântico-conceitual, que o insere em um espaço histórico-ideológico construído.

A palavra denegrir, nesse verbete do dicionário, sem dúvida, nos faz observar em seu campo semântico e em atos enunciativos, os possíveis efeitos de sentido, que contribuem para a apreensão de que a identidade forjada para o negro esteja associada à negatividade em relação ao branco. Desse modo, como a palavra denegrir inclui no seu campo semântico, também, difamar, tornar escuro, vinculando-a a tornar negro ou enegrecer, passa-se a assumi-la de forma preconceituosa, quando o falante a relaciona a conceitos pejorativos como manchar, macular, ficar negro, sujar, tirar o mérito de. Assim, o fato de atribuir-se uma concepção de mancha, mácula, sujeira ao negro, no discurso, essa atitude pode reforçar posicionamento ofensivo e racista. 
A discursividade é essencial, ao utilizar-se denegrir na cena enunciativa, lugar onde o enunciador busca agir sobre o co-enunciador, com o intuito de fazer prevalecer discursivamente os efeitos de sentido constitutivos do sujeito social. Em uma observação mais pontual, podemos dizer que a cena enunciativa se constitui como um território, onde os efeitos de sentido nos identificam como sujeitos negros ou brancos, caracterizam nossos corpos e a cor de nossa pele e acomodam nossos usos linguísticos. Enfim, para nós, denegrir está entre as palavras que, no dicionário brasileiro, no espaço sociocultural nacional e nas crenças dos falantes do português, nos movem a associá-la a determinações racistas contra o negro em relação ao branco, fazendo com que o racismo se legitime pelos sujeitos, em espaços de trocas, ou seja, socialmente, como uma forma de violência.

A relação entre a palavra e o sujeito que a enuncia pode ser compreendida sob dois pontos de vista: o primeiro relaciona-se ao envolvimento, que engaja o sujeito falante, o ouvinte e as condições sócio-históricas de produção do enunciado. O segundo refere-se ao sistema de restrições semânticas, que a palavra carrega no momento e na situação concreta de enunciação. Esses dois pontos de vista, indubitavelmente, se complementam, pois denotam modos de constituição discursiva. No entanto, reforça essa perspectiva, quando observamos, em Bakhtin (1998), a afirmação de que a palavra, apreendida no ato de fala, constitui um espaço discursivo de manifestação de ideologia, ou seja, o ato de dizer materializa diferentes formações discursivas que, segundo Foucault (2009, pp4344) são entendidas como um conjunto de regras anônimas, históricas, sempre determinadas no tempo e no espaço, que definiram uma época dada, e para uma área social, econômica e geográfica ou linguística dada, as condições de exercício da função enunciativa. 
Embora enunciada individualmente, cada sujeito falante, ao utilizar a palavra em seus atos de fala, coloca-se com fonte de referência pessoal, reflete sua cosmovisão e o posicionamento do grupo a que pertence, pois nenhuma palavra é neutra. Assim, é necessário considerarmos as formas de subjetivação, que não se prendem somente aos sujeitos falante e ouvinte, mas também aos efeitos do conteúdo semântico que a palavra carrega pois, de acordo com Maingueneau (2015, p.27), a fala é dominada pelo dispositivo de comunicação do qual ela provém. Para assumir a relação entre a palavra, o sujeito e o mundo, Wittgenstein (1968) adverte que o uso da palavra em diferentes interações linguístico-comunicacionais é que determina o seu sentido.

Trazemos agora a palavra negro/negra e ressaltamos algumas correlações semântico-discursivas, a fim de dar visibilidade ao funcionamento de sequências lexicais, que conotam uma negatividade social em seus aspectos particulares de compreensão. Etimologicamente, a palavra negro/negra tem sua origem no adjetivo latino niger, nigra nigrum, que significa negro, escuro, com pele escura, sóbrio, fúnebre. As sequências lexicais, que selecionamos partilham, socializam e naturalizam os mesmos efeitos de sentido de negro/negra, que se constroem na memória social.

A lista de sequências lexicais escolhidas - alma negra, asa negra, besta negra, lista negra, magia negra, ovelha negra, peste negra, câmbio negro, humor negro, mercado negro estão entre as corriqueiras no cotidiano social brasileiro e caracterizam-se por um funcionamento sintático específico, que se sujeita às situações enunciativas de uso. Nesse sentido, tais elocuções carregam conceituações e expressividades linguísticas (Desmet 1991 e 2002), que estão naturalizadas na língua e, por consequência, em nossa cultura, regulando nossa comunicação e, muitas vezes, fazendo com que os interlocutores não tenham consciência dessa realidade, mas que a compreendam discursivamente. 
Para nós, essa lista de sequências lexicais acima e outras semelhantes não mencionadas aqui evidenciam a relação sintática, que nelas opera e cujo processo de negociação de efeitos de sentido garante ao falante uma conscientização das condições de elocução pretendidas. $\mathrm{O}$ fato de o ser humano definir-se com um ser linguístico permite-lhe discernir a forma como a palavra materializa aspectos de sua existência e de sua atitude. Há uma clara conceituação do adjetivo negro/negra no Dicionário online de Língua portuguesa, como podemos constatar:

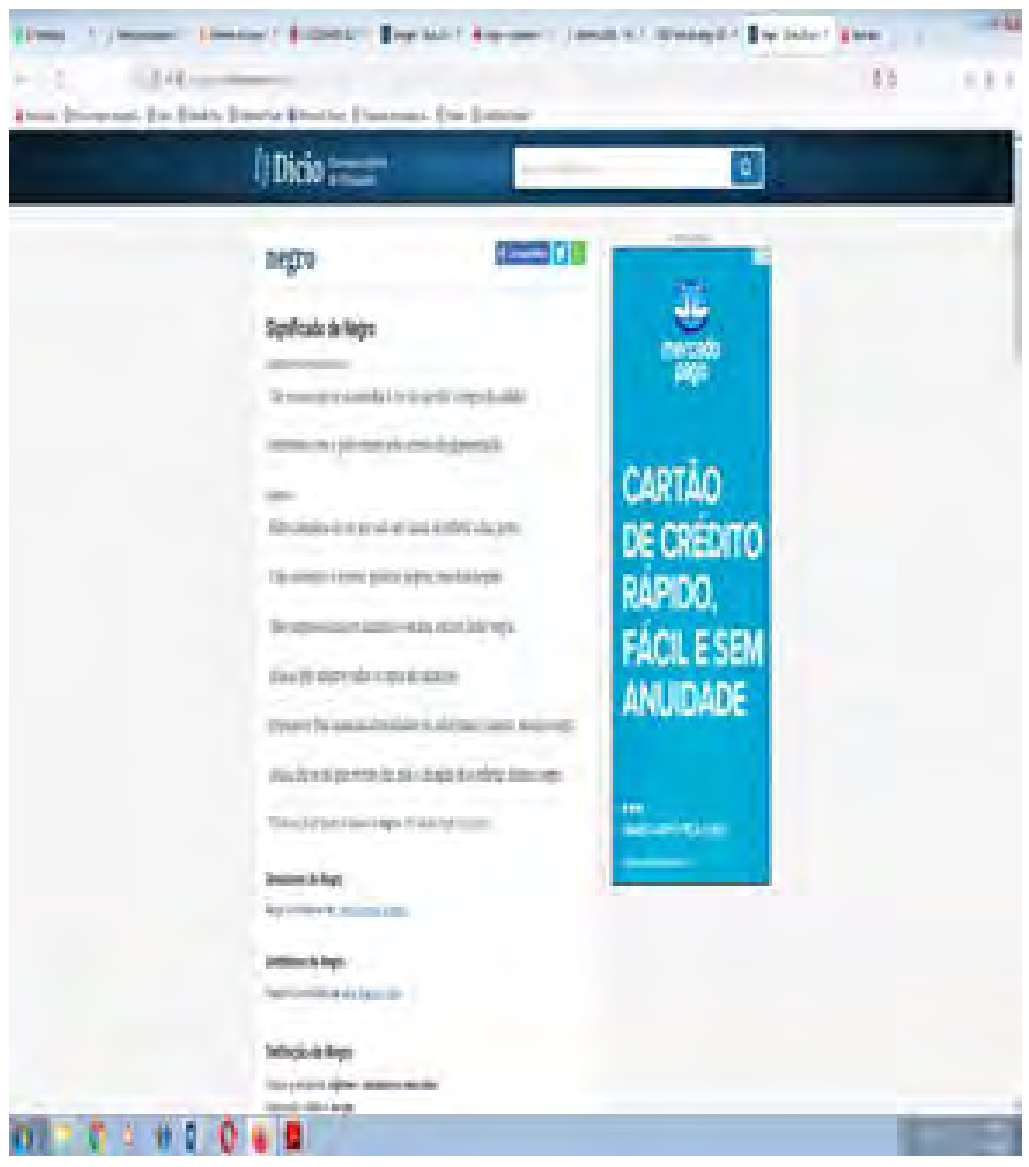


A palavra negro/negra, no verbete do dicionário, é apresentada em um campo semântico que a coloca como cor escura que se assemelha à cor do carvão, o negro do asfalto. Em seguida, o próprio verbete aponta para o indivíduo de pele escura pelo excesso de pigmentação. Essa relação do adjetivo e sua apreensão no indivíduo e, ainda, o sentido figurado de que anuncia adversidades ou infortúnios; funesto, destino negro nos faz considerar, com efeito, possibilidades de carregar, em atos enunciativos, possíveis efeitos de sentido, em que a figura do sujeito negro se associe a algo funesto em relação a seu antônimo alvo, branco, claro, subalternizando-o. Desse modo, parece-nos confirmar, a partir das referências postas pelo Dicionário, que as relações entre negro/branco ficam solidificadas na experiência sociocultural da população negra brasileira. Por isso, o fato de atribuir-se uma concepção de falta de cor, escuro, mancha ao negro, no discurso, pode expressar entendimento de posicionamento ofensivo, racista. Ianni (2004, p. 23), inclusive, sublinha que a ideologia racial determinada pelos brancos sintetiza o racismo, pois é a ideologia racial que articula e desenvolve a gama de manifestações, signos, símbolos ou emblemas com os quais indivíduos e coletividades "explicam", "justificam", "racionalizam", "naturalizam" ou "ideologizam" desigualdades, tensões e conflitos raciais.

A relação sintática entre o substantivo e o adjetivo negro/negra, conforme a lista que selecionamos, predispõe-nos a identificar situações enunciativo-discursivas, que estão naturalizadas, no cenário sociocultural brasileiro, como marcas de expressividade em relação às ações que estão associadas. Essas sequências lexicais, abertas a diferentes efeitos de sentido, embora amplie seu campo semântico-lexical, pode negociar e fabricar, nos atos de fala, atitudes, conflitos raciais e comportamentos racistas. Queremos acentuar que o uso dessas sequências lexicais não pode ser entendido, de forma ingênua, pois o emprego dessas unidades lexicais, mesmo inconsciente, fere a dignidade de sujeito negro. 
Embora não possamos dizer que não haja restrições, a carga negativa decorrente do campo semântico-lexical imposto ao adjetivo negro/negra, com descrito no Dicionário, compromete os substantivos, que formam uma unidade lexical com ele, tornando-os mais produtivos na enunciação, como observamos no Quadro a seguir:

\begin{tabular}{|l|l|}
\hline Alma negra & Pessoa má sucedida \\
\hline Asa negra & $\begin{array}{c}\text { Pessoa que tem olho grande e quando se aproxi- } \\
\text { ma dá tudo errado, olhudo, azarão, pé frio; } \\
\text { pessoa que prejudica ou embaraça um gru- } \\
\text { po com frequência. }\end{array}$ \\
\hline Besta negra & Inimigo, problema de difícil solução \\
\hline Lista negra & $\begin{array}{l}\text { Relação de coisas ou pessoas consideradas pre- } \\
\text { judiciais }\end{array}$ \\
\hline Magia negra & Bruxaria, feitiçaria \\
\hline Ovelha negra & $\begin{array}{l}\text { Pessoa ou entidade que se destaca pelo mau } \\
\text { procedimento }\end{array}$ \\
\hline Peste negra & Doença que assolou a Europa na Idade Média \\
\hline Câmbio negro & Comércio ou transação ilegal \\
\hline Dia negro & Dia em que ocorrem situações desagradáveis. \\
\hline Humor negro & $\begin{array}{l}\text { Humor associado ao sarcasmo, a situações trá- } \\
\text { gicas, desastrosas }\end{array}$ \\
\hline Mercado negro & Comércio ilegal \\
\hline
\end{tabular}

O que constatamos nas sequência lexicais do Quadro acima é que, ao menos no nível da carga semântica dicionarizada, a palavra negra/negro negocia, histórica e culturalmente, efeitos de sentido negativo. Dessa maneira, os efeitos de sentido impostos a favor de aspectos negativos sobre a palavra negro/negra são argumentos baseados na historicidade, que são legitimados por um conjunto de atitudes partilhadas no contexto brasileiro, quando falamos de discriminação e racismo. 
Além disso, o que podemos constatar, ao menos conscientemente, é que o falante não tem necessidade de saber se a palavra negro/negra carrega um posicionamento racista, embora ele o entenda. Na verdade, é necessário considerar como critério de distinção a relação entre o efeito de sentido de uma palavra, na enunciação, e aqueles materializados nos dicionários, onde o sentido é, mais facilmente, compartilhado.

Nesse capítulo, colocamos em discussão o estudo de palavras e de sequências lexicais como integrantes de um processo sócio-histórico-cultural, incluindo nele o sujeito negro e os efeitos de sentido racistas que recaem sobre ele nas cenas enunciativas. Discutir sobre os efeitos de sentido de determinadas palavras e sequências lexicais permitiu-nos identificar como elas agem sobre o sujeito negro, inferiorizando-o hierarquicamente. Como pudemos investigar, com base em uma perspectiva discursivo-cultural e léxico-semântica, a palavra e as sequências lexicais funcionam, no dicionário, como uma possibilidade de projeção de um uso de referência, em oposição ao que ocorre nas cenas enunciativas, espaço em que se marcam posicionamentos determinados pela posição-sujeito.

A vinculação de nosso estudo à Análise do Discurso de linha francesa e aos Estudos Culturais oportunizou-nos uma interdisciplinaridade com a perspectiva léxico-semântica, que nos motivou apontar questões de racismo, construído na/pela linguagem. Como o dicionário não contempla o funcionamento linguageiro, pois sua função é uma tentativa de descrição do léxico (Biderman (2001, p.132), para dar conta dos objetivos que propusemos, foi-nos necessário recorrer à categoria de cena enunciativa, pois nela se refletem questões de ordem sócio-históricas e culturais de sujeitos negros e brancos, que nos pareceram determinantes no tratamento do debate sobre o racismo. 
Por isso, como as palavras e as sequências lexicais negociam efeitos de sentido na enunciação elas, por conseguinte, refletem posicionamentos histórico-culturais e naturalizam atitudes particulares de determinados sujeitos. Dessa maneira, ao colocar em funcionamento a língua, o falante organiza o discurso, adequando as palavras em relação aos efeitos de que quer gerenciar na interlocução. Nossa discussão mostrou que há uma articulação entre as palavras encenadas e o investimento em posicionamentos. Com isso, sintetizamos nossa reflexão, afirmando que não podemos considerar as palavras apenas dicionarizadas. É fundamental entendê-las enunciativamente, na medida em que a discursivização torna-se uma condição para reconhece-las como produtoras de efeitos de sentido. Em relação ao questionamento que propusemos, nesse capítulo, sobre a palavra e as sequências lexicais, devemos esclarecer, finalmente, que a língua é autônoma e, se há um racismo decorrente do uso linguístico, é porque a língua, por inscrever-se em um processo de discursivização, materializa efeitos de sentido resultantes do uso, da história e da cultura dos sujeitos falantes.

\section{Referências}

ADAM, Michel. Racisme et catégories du genre humain. L 'homme et la société, 24 (2): 77-96, 1984.

ALMEIDA, Silvio. Racismo estrutura. São Paulo: Pólen, 2019.

ARAUJO, Emanoel. Viva Cultura, Viva o Povo Brasileiro. Museu Nacional: São Paulo, 2007.

BAKHTIN, Mikhail. Marxismo e filosofia da linguagem. 8. ed. São Paulo: Hucitec, 1988.

BIDERMAN, M.T.C. Teoria linguística: teoria lexical e Linguística computacional. São Paulo: Martins Fontes, 2001.

BOBBIO, Norberto. Teoria geral da política: a filosofia política e as lições 
dos clássicos. Organizado por Michelangelo Bovero. Tradução de Daniela Beccaccia Versiani. Rio de Janeiro: Campus, 2000.

BRETON. Phillippe. A manipulação da palavra. Trad. Maria Stela Gonçalves. São Paulo: Loyola, 1999.

BRETON. Phillippe. Elogio da palavra. Trad. Nicolas Nyimi Campanário. São Paulo: Loyola, 2006.

CASARES SÁNCHEZ, J. Introducción a la lexicografía moderna. Madrid: CSIC, 1950.

CHARAUDEAU, Patrick. Uma teoria dos sujeitos da linguagem. In: MARI, H., MACHADO, I. L., MELLO, R. (orgs.) Análise do discurso: fundamentos e práticas. Belo Horizonte: NAD, FALE/ UFMG, 2001.

DESMET, Isabel. Terminologia e fraseologia: tendências atuais. Terminologia. número 3-4. TERMIP, 1991.

DESMET, Isabel. Teoria e prática de fraseologia de especialidade: aplicações. Filologia Linguística portuguesa. n. 5, p.27-56, 2002.

FANON, Frantz. Pele negra, máscaras brancas. Tradução de Renato da Silveira. Salvador: EDUFBA, 2008.

FOUCAULT, Michel. A Arqueologia do saber. Rio de Janeiro: Forense Universitária, 2009.

GREIMAS, A.J. Sobre o sentido. Petrópolis: Vozes, 1975.

IANNI, Octavio. Dialética das relações raciais. In: Estudos Avançados 18 (50), pp 21-30, 2004.

LABELLE, Micheline. Idéologie de Couleur et Classes Sociales en Haïti. Montréal: Les Presse de l'Université de Montréal, 1987.

LEFFA, V. J. Aspectos externos e internos da aquisição lexical. In: LEFFA (Org.) As palavras e sua companhia: o léxico na aprendizagem. Pelotas: Educat, 2000, p. 15-44.

MAINGUENEAU, Dominique. El ethos y la voz de lo escrito. Version. Estúdios de Comunicación y Política. n. 6. México: Universidad Autónoma Metropolitana-Xochimilco, 1996, p. 79-86.

MAINGUENEAU, Dominique. Gênese dos discursos. Curitiba: Criar, 2005. 
MAINGUENEAU, Dominique. Cenas da Enunciação. Organizado por Sírio Possenti e Maria Cecília Pérez de Souza-e-Silva, diversos tradutores. Curitiba: Criar, 2006.

MAINGUENEAU, Dominique. Discurso e análise do discurso. Tradução de Sírio Possenti. São Paulo: Parábola, 2015.

MARI, Hugo. Os lugares do sentido. Campinas: Mercado das Letras, 2005.

NASCIMENTO, Jarbas Vargas \& FERREIRA, Anderson (orgs). Discurso e Cultura. Vol.2. São Paulo: Blucher, 2019.

OLIVEIRA, Ana Maria Pinto Pires de \& ISQUERDO, Aparecida Negri (orgs). As ciências do léxico: Lexicologia, Lexicografia e Terminologia. Campo Grande - MS: EUFMS, 2001.

ORLANDI, Eni Pulchinelli. Análise do Discurso: princípios e procedimentos. Campinas, SP: Pontes, 2003.

RANAURO, Margarida. A palavra como caminho. Rio de Janeiro: Rocco, 2007.

RIBEIRO, Djamila. Lugar de fala. São Paulo: Pólen, 2019.

RODRIGUES. Sérgio. A palavra negro deve ter nascido no escuro da noite. https://veja.abril.com.br/blog/sobre-palavras/a-palavra-8216-negro-8217-pode-ter-nascido-no-escuro-da-noite/2020. Acesso 30 de julho de 2021

TURAZZA, Jeni Silva. Léxico e criatividade. São Paulo: Annablume, 2005.

VILELA, Mário Augusto Quinteiro. Léxico e gramática. Coimbra: Almedina, 1994.

WITTGENSTEIN, Ludwig. Tractatus Logico-Philosóphicus. Tradução e Apresentação José Arthur Giannotti. São Paulo: EDUSP, 1968.

link: https://www.migalhas.com.br/coluna/gramatigalhas/230154/negro---e-pejorativo-e-racista 
